of C-terminal telopeptide of type I collagen (CTX). Its place in the formation of osteoporosis in SLE patients is poorly understood, as well as its relationship with the course of the disease.

Objectives: The aim of study was to determine serum level of CTX in the SLE patients and its relationship with structural and functional state of bone tissue, course of the disease.

Methods: The study involved 58 SLE women (study group) and 29 healthy individuals (control group) representative by age and gender. The mean age of patients was $45,11 \pm 1,03$ years. For every patient data were recorded on age, body mass index (BMI), chronic SLE damage (SLICC/ACR DI) and disease activity score (SLEDAI), cumulative glucocorticoid dose, serum concentrations of interleukin-6 (IL-6) and C-reactive protein (CRP), bone resorption marker (CTX). Serum concentration of CTX was determined using ELISA test system "Nordic Bioscience Diagnostics A/S". Changes in BMD of the lumbar spine and proximal hip were determined by Dual-energy X-ray absorptiometry.

Results: It was established, that in patients with SLE serum level of C-terminal telopeptide of type I collagen was $1,15 \pm 0,03 \mathrm{ng} / \mathrm{ml}$, while in the control group $0,83 \pm 0,03 \mathrm{ng} / \mathrm{ml}$, or was higher more than $19,0 \%$. Violation of bone remodeling in patients with SLE was associated with reduced BMD, increased incidence of osteopenia and osteoporosis. Thus, the mean concentration of CTX in patients with osteoporosis was $1,63 \pm 0,04 \mathrm{ng} / \mathrm{ml}$, while in patients with normal bone $1,0 \pm 0,03 \mathrm{ng} / \mathrm{ml}$. In SLE patients with osteopenia the level of C-terminal telopeptide of type I collagen was 1,23 $\pm 0,04 \mathrm{ng} / \mathrm{ml}$ (higher more than $23 \%$ compared with the control group). Increased CTX practically had no correlation with age, duration of the disease, smoking and BMI. At the same time the serum CTX was associated with chronic SLE damage index $(r=0,51)$, SLEDAl disease activity $(r=0,41)$, concentration of IL-6 $(r=0,45)$ and $\mathrm{CRP}(r=0,44)$

Conclusions: Alterations of bone metabolism were found in $19 \%$ female SLE patients in the form of increasing serum CTX and closely associated with the severity and activity of the disease, high levels of CRP and IL-6 and did not depend on the age, disease duration, smoking and body mass index.

Disclosure of Interest: None declared

DOI: 10.1136/annrheumdis-2017-eular.5770

\section{AB0515 SKIN MANIFESTATIONS AS INDEPENDENT PREDICTORS AND THE INITIAL RISK FAKTORS FOR SYSTEMIC ANTIPHOSPHOLIPID EVENTS}

L. Stojanovich, A. Djokovic, N. Stanisavljevic, M. Zdravkovic. Internal Medicine Department, University Hospital Center Bezanijska Kosa, Belgrade, Serbia

Background: Antiphospholipid syndrome (APS) patients express skin manifestations with the presence of various levels of antiphospholipid antibodies (aPL).Several studies have shown the frequency of dermatological manifestations with $\mathrm{APS}^{1,2,3}$, including livedo reticularis, cutaneous ulcers, acrocyanosis, and other.

Objectives: Dermatological manifestations can be the initial clue in the diagnosis of this disease.

Methods: Our study includes a total of 508 APS patients; 360 were PAPS patients (283 female and 77 male, mean age $44.0 \pm 12.9$ years), 148 had APS associated with SLE/SAPS (133 female and 15 male,mean age $47.7 \pm 14.8$ years).aPL analysis included:LA, aCL (lgG/lgM), $\beta_{2} \mathrm{GPI}(\operatorname{lgG} / \lg M)$. In all patients, we collected data considering frequently occured skin lesions.

Results: Our results showed prevalence of skin manifestations in SAPS group of patinenst regading to PAPS (Table 1). Patients with skin manifestations overall had higher prevalence of thrombosis (Table 2).

Table 1. Prevalence of skin manifestations analyzed in PAPS and SAPS group

\begin{tabular}{lccc}
\hline & PAPS $(\mathrm{N}=360)$ & SAPS $(\mathrm{N}=148)$ & $\mathrm{p}$ \\
\hline Livedo & $46(12.8 \%)$ & $86(58.1 \%)$ & $\mathbf{0 . 0 0 0 1}$ \\
Skin ulcerations & $31(8.6 \%)$ & $47(31.8 \%)$ & $\mathbf{0 . 0 0 0 1}$ \\
Pseudovasculitis lesions & $34(9.4 \%)$ & $72(48.6 \%)$ & $\mathbf{0 . 0 0 0 1}$ \\
Superfitial cutaneous necrosis & $9(2.5 \%)$ & $25(16.9 \%)$ & $\mathbf{0 . 0 0 0 1}$ \\
Digital gangrene & $3(0.8 \%)$ & $14(9.5 \%)$ & $\mathbf{0 . 0 0 0 1}$ \\
Skin manifestations overall & $98(27.2 \%)$ & $113(76.4 \%)$ & $\mathbf{0 . 0 0 0 1}$ \\
\hline
\end{tabular}

Table 2. Skin manifestations and thrombosis

\begin{tabular}{lcc}
\hline & PAPS $(\mathrm{p}$ values) & SAPS ( $\mathrm{p}$ values) \\
\hline Livedo & 0.038 & 0.062 \\
Skin ulcerations & 0.024 & $\mathbf{0 . 0 0 4}$ \\
Pseudovasculitis lesions & 0.007 & $\mathbf{0 . 0 1 9}$ \\
Superfitial cutaneous necrosis & 0.005 & 0.380 \\
Digital gangrene & 1.000 & $\mathbf{0 . 0 0 8}$ \\
Skin manifestations overall & 0.0001 & $\mathbf{0 . 0 7 6}$ \\
\hline
\end{tabular}

Conclusions: Dermatological manifestations can be very often the initial symptoms of severe manifestations of APS.Our study showed that patients with secondary APS had higher prevalence of skin lesions, and that some aPL types were risk factors for thrombotic manifestations in APS patients

\section{References:}

[1] Toubi E, Krause I, Fraser A, Lev S, Stojanovich L, Rovensky J, et al. Livedo reticularis is a marker for predicting multi-system thrombosis in antiphospholipid syndrome. Clin Exp Rheumatol 2005;23:499-504.
[2] Weinstein S, Piette W. Cutaneous manifestations of antiphospholipid antibody syndrome. Hematol Oncol Clin North Am 2008;22:67-77.

[3] Asherson RA, Cervera R, Klumb E, Stojanovich L. et all.: Amputation of Digits or Limbs in Patients with Antiphospholipid Syndrome. 21 January 2008. Seminars in Arthritis and Rheumatism. 2008; 38: 124-31.

[4] Stojanovich L, Markovic O, Marisavljevic D et all. Influence of antiphospholipid antibody levels and type on thrombotic manifestations: results from the Serbian National cohort study. Lupus 2011;0: 1-8.

[5] Stojanovich L, Kontic M, Djokovic Aet all. Association between Systemic Non-criteria APS Manifestations and Antibody Type and Level: Results from the Serbian National Cohort Study. Clinical and Experimental Rheumatology, 2013,31(5):756-60.

Acknowledgements: This work was supported by research grant number 175041 for 2011 - 2017, issued by the Ministry of Science of the Republic of Serbia.

Disclosure of Interest: None declared

DOI: 10.1136/annrheumdis-2017-eular.2759

\section{AB0516 INCIDENCE OF CANCER IN A COHORT OF PATIENTS WITH PRIMARY SJÖGREN SYNDROME}

M. Brom, S. Moyano, M. Scolnik, L.E. Pompermayer, I.J. Gandino, E.R. Soriano. Rheumatology, Hospital Italiano de Buenos Aires, Ciudad Autónoma de Buenos Aires, Argentina

Background: The most severe complication of Sjögren Syndrome is the development of lymphoproliferative processes. Several neoplasia have been associated with the disease, being non-Hodgkin lymphoma the most frequent one.

Objectives: Our objective was to evaluate incidence of cancer in a cohort of patients with primary Sjögren Syndrome.

Methods: A retrospective descriptive study was performed in a university hospital with its own health insurance and captive population. Using electronic medical records and laboratory database were review the entries performed between $01 / 01 / 2000$ and 12/31/2015. We analyzed those patients with either diagnosis of Sjögren Syndrome, complain of dry mouth/eyes, or positive antibodies antiRo/SSA and anti-LA/SSB.

Among these patients, we included those fulfilling either ACR 2012 or EULAR 2002 Sjögren criteria, or those who were diagnosed as Primary Sjögren Syndrome by the treating rheumatologist even if they did not fulfill criteria.

We then proceeded to register and analyze demographic, clinical and histopathologic information available on their clinical records.

Results: One hundred fifty-seven patients with Primary Sjögren Syndrome were identified. Female accounted for $95.5 \%$ of the cohort; mean age at diagnosis was 49.4 years (SD 19). Median follow-up time was 7.7 years (IQR 8). The development rate and type of neoplasia was the following:

- Lymphomas: Three (Two MALT lymphomas of the parotid and one disseminated non-Hodgkin lymphoma). Density of Incidence 260/100,000 person/year (Cl 95\%: 50 - 750/100,000 person/year)

- Multiple Myeloma: One

- Skin (non-melanoma) neoplasia: Fou

- Solid organ Neoplasia: Seven (Four breast cancer, one lung cancer, one uterus cancer, one tongue cancer). Density of Incidence 600/100,000 person/year (CI $95 \% 240-1240 / 100,000$ person/year)

Univariate analysis showed association between lymphoma and cryoglobulinemia $(p=0.01 ; O R=5,8)$, low $C 4$ fraction of complement $(p=0.01 ; O R=5,1)$, anemia $(p=0.02 ; O R=1,96)$ and leucopenia $(p=0.03 ; O R=1,67)$

Conclusions: Development of cancer is a known complication of Primary Sjögren Syndrome. The association between lymphoma and cryoglobulinemia, low C4 fraction of complement, anemia and leucopenia enhances the importance of periodic screening for neoplasms among this subgroup of patients with Primary Sjögren Syndrome.

Disclosure of Interest: None declared

DOI: 10.1136/annrheumdis-2017-eular.3195

\section{AB0517 PREDICTIVE FACTORS FOR INFECTION IN SYSTEMIC LUPUS ERYTHEMATOSUS}

M. Kechida ${ }^{1}$, N. Lorenzo ${ }^{2}$, R. Klii ${ }^{1}$, S. Hammami ${ }^{1}$, I. Khochtali ${ }^{1} .{ }^{1}$ Internal Medicine and Endocrinology Department, Fattouma Bourguiba Hospital, Monastir, Tunisia; ${ }^{2}$ Internal Medicine and cancerology Department, Saint-Cyr Hospital, Lyon, France

Background: it's known that infection could complicate the course of systemic lupus erythematosus (SLE) because of the immune status or the long term steroids and immunosuppressors.

Objectives: This study was aiming at determining the prevalence of infectious complications during SLE and their predictive factors.

Methods: A retrospective bi-centric analyzes of 289 patients diagnosed as SLE between January 2004 and December 2016 according to the ARA criteria of 1997 was conducted. A descriptive analysis of infectious complications was first made, then a comparative study between patients with (group 1) and without (group 2) infectious complications was performed to detect predictive factors.

Results: Mean age was $84.6 \pm 13$ years (14-72 years) with a sex ratio $F / M=6$ 